\title{
OS MÉTODOS DO DIREITO COMPARADO: POR UM PLURALISMO METODOLÓGICO E UM COMPARATIVISMO CRÍTICO
}

\section{COMPARATIVE LAW METHODS: METHODOLOGICAL PLURALISM AND A CRITICAL COMPARATISM}

\author{
Paula Brener ${ }^{1}$ \\ Henry Colombi ${ }^{2}$ \\ Marcelo Maciel Ramos ${ }^{3}$
}

\section{RESUMO}

A intensificação das interações a nível mundial conferiu ao Direito Comparado um novo destaque e relevância, do qual emergem diversos questionamentos, principalmente acerca de quais as formas de empreender um estudo comparado de forma consistente e segura. O presente trabalho busca sistematizar, de modo didático, diferentes métodos do Direito Comparado, evidenciando suas técnicas, suas vantagens e seus perigos. Dessa forma, pretende-se auxiliar estudantes e pesquisadores interessados na pesquisa comparada, chamando atenção para os cuidados a serem tomados para que se evitem problemas na comparação. Foram analisados os métodos funcionalista, estruturalista e hermenêutico, apontando as hipóteses em que cada um desses pode ser melhor empregado. O Direito Comparado pode ser um instrumento profícuo de reflexão sobre o direito do outro e sobre o próprio ordenamento, além de permitir o aprimoramento das instituições e institutos, desde que observados cuidados imprescindíveis para assegurar sua coerência. $\mathrm{O}$ estudo de cada um desses métodos permite ao comparatista melhor compreender sua própria análise e evitar problemas que comumente se identificam na aplicação desses métodos. Por fim, a título conclusivo, aponta-se que a adoção de um pluralismo metodológico e de um comparativismo crítico, que conjuguem as principais vantagens de cada método para a análise a ser realizada, pode fornecer a melhor opção àquele que pretende enveredas pelos caminhos da comparação jurídica.

Palavras-chave: Direito Comparado. Método Funcionalista. Método Estruturalista. Método Hermenêutico.

\section{ABSTRACT}

The intensification of interactions world wide has given Comparative Law a new prominence and relevance, from which several questions emerge, mainly about the ways to undertake a comparative study in a consistent and safe way. The present work seeks to systematize, in a didactic way, different methods of Comparative Law, bringing forward its techniques, advantages and dangers. Thus, it is intended to assist students and researchers

\footnotetext{
${ }^{1}$ Doutoranda pela Faculdade de Direito da Universidade Federal de Minas Gerais (UFMG). Mestre pela Faculdade de Direito da UFMG. Advogada criminalista.

${ }^{2}$ Doutorando e Mestre em Direito pela Universidade Federal de Minas Gerais (UFMG). Advogado.

${ }^{3}$ Professor Adjunto da Faculdade de Direito da Universidade Federal de Minas Gerais. Bacharel, Mestre e Doutor em Direito pela UFMG, tendo realizado parte de suas pesquisas doutorais no Institut de la Pensée Contemporaine da Université Paris-Diderot. Atualmente, leciona disciplinas nos cursos de Direito, de Ciências do Estado e no Programa de Pós-graduação em Direito da UFMG, onde está habilitado a orientar dissertações de mestrado e teses de doutorado. É coordenador do Grupo de Pesquisa Kritikos - Teorias Críticas do Direito e do Programa de Extensão Diverso UFMG - Núcleo Jurídico de Diversidade Sexual e de Gênero. É membro do Projeto Coletivo Filosofia do Poder e Pensamento Radical do Programa de Pós-Graduação em Direito da UFMG e do Projeto Inclusionary Practices, desenvolvido na UFMG e na University of Kent, no Reino Unido.
} 


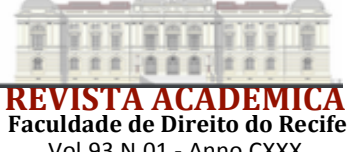

Vol.93 N.O1

interested in comparative research, calling attention to the precautions to be taken in order to avoid problems in the comparison. The functionalist, structuralist and hermeneutical methods will beanalyzed, pointing out the hypotheses in which each of these can be better employed. Comparative Law can be a useful instrument for criticaly assessing both foreign and domestic law, in addition to allowing the improvement of institutions and institutes, provided that essential care is observed to ensure their coherence. The study of each of these methods allows the comparator to better understand his own analysis and avoid problems that are commonly identified in the application of these methods. Conclusively, it is pointed out that the adoption of a methodological pluralism and a critical comparativism, which combine the main advantages of each method for the analysis to be performed, can provide the best option for those who intend to take the paths legal comparison.

Keywords: Comparative Law. Functionalist method. Structuralist Method. Hermeneutical Method.

\section{INTRODUÇÃO}

A diversidade das culturas e dos ordenamentos normativos em um mundo cada vez mais globalizado, assim como as tensões que dela decorrem, tem feito renascer o interesse e a importância do Direito Comparado. Nesse contexto, o Direito Comparado passa a ser pensado e repensado como instrumento dinâmico de novas e antigas ambições, tais como: a promoção das perspectivas universalizantes do Direito ocidental (ANCEL, 1980, p. 17-18); a assimilação, harmonização e mesmo uniformização do Direito (VOGEL, 2002, p. 113 et seq.); a construção de um Direito Internacional comum; a reforma e adequação de ordenamentos nacionais às exigências da globalização acelerada do tempo presente (CHIESA, 2014, p. 1091); o fomento do conhecimento da diversidade das culturas e ordens normativas; e as reflexões acadêmicas críticas em relação aos direitos locais e internacionais. Além disso, os novos conhecimentos das Ciências Sociais e as teorias críticas do Direito vêm provocando uma verdadeira renovação dos métodos comparatistas nas últimas decadas.

Esse cenário, no entanto, reintroduz velhas questões, atualizadas a luz de novos desafios: qual é a forma adequada e os problemas enfrentados para se lançar no estudo do direito do outro? Há um modo correto ou vários caminhos para sefazer direito comparado? Enfim, quais são os métodos para uma investigação comparativista?

Diante dessas indagações que inspiram o presente trabalho, procura-se a seguir sintetizar neste artigo as técnicas e caminhos disponíveis para a realização do Direito Comparado, destacando-se as vantagens e perigos de cada abordagem e os cuidados que devem ser tomados em sua utilização. Com isso, busca-se fornecer um auxílio introdutório para estudantes e pesquisadores que necessitam constantemente lançar mão do recurso da comparação normativa em seus trabalhos. Como se verá, todos os métodos disponíveis para as análises comparatistas apresentam vantagens e padecem também de falhas. Portanto, esse trabalho não se propõe a apontar o melhor método, mas sim empreender uma apresentação dos principais modelos, a fim de disponibilizar opções metodológicas para que comparatistas não fiquem a depender apenas do "julgamento sensato, do bom senso ou mesmo da intuição" (ZWEIGERT; KÖTZ, 1998, p. 33, tradução nossa $)^{4}$. A título conclusivo evidencia-se que não é possível compreender adequadamente os complexos elementos que compõem as diferentes tradições jurídicas fora do quadro de um pluralismo metodológico e de um comparativismo crítico.

Para esse propósito, dividimos o texto em quatro partes, além da introdução e conclusão. Na primeira parte, apresentamos uma explanação geral do conceito de método e suas questões no

${ }^{4}$ No original: "[...]an area where only sound judgement, common sense, or even intuition can be of any help". 
âmbito do Direito Comparado, a fim de introduzir três das suas principais perspectivas metodológicas. Em seguida, trataremos do funcionalismo que é, ao mesmo tempo, o mais difundido e criticado método de Direito Comparado. Na terceira parte, abordaremos a perspectiva estruturalista, confrontando-a com o estruturalismo da Antropologia de Levy-Strauss. $\mathrm{Na}$ quarta parte, discutiremos o método hermenêutico, o qual valoriza fortemente o contextualismo e tem como maior expoente Pierre Legrand.

\section{O MÉTODO EM DIREITO COMPARADO}

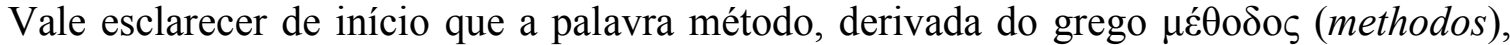

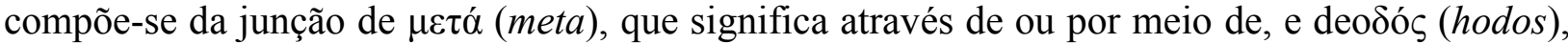
que comunica a ideia de via ou caminho. Nicola Abbagnano define método como "procedimento de investigação organizado, repetível e autocorrigível que garanta a obtenção de resultados

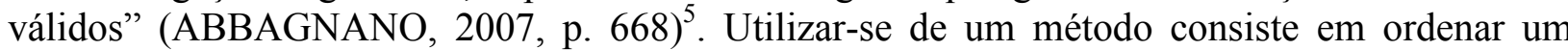
trajeto de investigação de modo a se garantir o controle dos dados, informações e variáveis que influem no seu resultado ou conclusões finais. A modernidade transformou o método em verdadeira condição do saber científico, mesmo daqueles produzidos pelas ciências sociais e normativas, como é o caso do Direito. Desse modo, a metodologia se apresenta como essa tentativa, muitas vezes frustrada para as ciências humanas, de diferenciar o verdadeiro e o falso no caminho da formação do saber científico.

$\mathrm{Na}$ esteira das ciências ocidentais, obstinadas pela busca de um método universal único que pudesse garantir maior certeza em relação a sua pretensão de verdade, o Direito esteve sempre propenso a buscar caminhos que fundamentassem a imposição de normas universalmente válidas. Essa perspectiva marcou fortemente a tradição clássica do Direito Comparado, conforme se evidencia nos discursos de dois dos mais importantes comparatistas, Zweigerte Kötz (1998).

Todavia, os esforços empreendidos para formar um sistema legal universal ou definir uma metodologia única parecem não ter passado de uma utopia fadada ao fracasso. Nas últimas décadas, o que tem prevalecido é uma abordagem mais plural e flexível em relação aos métodos do Direito Comparado ${ }^{6}$. Ainda que, como à frente se apontará, prevaleça no Direito Comparado o método funcionalista, consolidado desde os trabalhos de Zweigert e Kötz (1998), é necessário ter em mente que não há um caminho de investigação aceito de forma unânime pelos estudiosos da área (SAMUEL, 2014, p. 79). O que se observa é, na verdade, a existência de um pluralismo de métodos e perspectivas ${ }^{7}$.

Por essa razão, nos parece preferível que qualquer um que pretenda comparar direitos deva conhecer os diferentes métodos desenvolvidos não só por juristas comparatistas, mas também por cientistas sociais. Afinal, o fato de não haver um consenso sobre o método não afasta de forma alguma a necessidade de se estar consciente e crítico em relação aos meandros da comparação. Uma compreensão ampla dos caminhos possíveis para se fazer investigações em Direito Comparado e o uso combinado e crítico de alguns deles conduzirá a resultados e análises mais consistentes em relação ao direito do outro, conforme se demonstrará a seguir.

${ }^{5}$ Geoffrey Samuel entende método como o "esquema de inteligibilidade", expressão empregada pelo pensamento sociológico a qual se refere à forma pela qual são representado após interpretação a forma natural ou os fatos sociais percebidos. (SAMUEL, 2014, p. 81).

${ }^{6}$ Cf. Jaakko Husa (2007) e Geoffrey Samuel (2014).

${ }^{7}$ Cf.Konrad Zweigert e Hein Kötz (1998), Ralf Michaels (2006), Pierre Legrand (2003), Geoffrey Samuel (2014), Jaakko Husa (2007).

BRENER, Paula; COLOMBI, Henri; RAMOS, Marcelo Maciel. OS MÉTODOS DO DIREITO COMPARADO: POR UM PLURALISMO METODOLÓGICO E UM COMPARATIVISMO CRÍTICO. Revista Acadêmica da Faculdade de Direito do Recife ISSN: 2448-2307, v. 93, n.1, p.212-226 Abr. 2021. ISSN 2448-2307. <Disponível em: https://periodicos.ufpe.br/revistas/ACADEMICA/article/view/249545> 


\section{O MÉTODO FUNCIONALISTA}

O funcionalismo é o método mais difundido entre comparatistas, tendo exercido forte influencia para o desenvolvimento do Direito Comparado enquanto disciplina. Zweigert e Kötz chegaram a afirmar que "o princípio básico de todo direito comparado é o da funcionalidade" (1998, p. 34). No entanto, os debates acerca do funcionalismo são pouco precisos quanto ao seu próprio significado e suas variadas vertentes. É importante ressaltar que o funcionalismo é um método que se desenvolveu no âmbito de diversas disciplinas, não tendo jamais constituído uma exclusividade do Direito Comparado. Ralf Michaels identifica sete espécies de funcionalismo, encontradas em diversas disciplinas e objetivando diferentes finalidades, que merecem ser aqui transcritos como ponto de partida da nossa análise:

(1) finalismo, um funcionalismo neo-aristotélico baseado em uma teleologia inerente, (2) adaptacionismo, um funcionalismo evolucionista, dentro da tradição Darwinista, (3) funcionalismo clássico (Durkheimiano), que explica as instituições por sua utilidade à sociedade, (4) instrumentalismo, uma teoria normativa que prega o uso da lei como engenharia social, (5) funcionalismo refinado, um método funcionalista que substitui alguns postulados do funcionalismo clássico por hipóteses que podem ser empiricamente testadas, (6) funcionalismo epistemológico, uma epistemologia focada em relações funcionais, e não em na ontologia das coisas, e (7) funcionalismo equivalente, assentado sobre estes conceitos, mas enfatizando o aspecto não teleológico e não causal das relações funcionais ${ }^{8}$. (MICHAELS, 2006, p. 344-345, tradução nossa)

Esses conceitos foram empregados em diferentes contextos, servindo a necessidades e fins diversos. Percebem-se avanços sucessivos nestas formulações, na medida em que se supera algumas das dificuldades do método, como o abandono da visão teleológica e a busca por maior possibilidade de comprovação empírica dos resultados obtidos. No entanto, deve-se manter em mente que foi a partir da conexão com os saberes produzidos em outras disciplinas, sobretudo no âmbito das Ciências Sociais, que o Direito Comparado passou a se valer do método funcionalista. Essa transposição entre o que se produziu em termos de funcionalismo no âmbito de outras ciências, confrontado com sua produção no que se refere aos estudos jurídicos comparativos não se deu, no entanto, de modo totalmente coerente.

Os comparatistas tendem a empregar indistintamente em suas investigações características de diversas vertentes do funcionalismo, muitas vezes incompatíveis entre si. Essa é a crítica formulada por Ralf Michaels, ao alegar que o método funcionalista aplicado ao Direito Comparado trata, na realidade, não de uma síntese, mas sim de um ecletismo. Aproveita-se de fragmentos avulsos das diferentes vertentes do funcionalismo desenvolvido por outras ciências, utilizando-se deles como elementos de comparação sem qualquer critério preciso. Isso se deve, na maioria dos casos, ao viés mais pragmático assumido pelo Direito Comparado, menos preocupado com questões metodológicas e epistemológicas (MICHAELS, 2006, p. 362).

Apesar do ecletismo, que parece ser uma marca do funcionalismo aplicado ao Direito, podemos identificar neste método pelo menos três elementos que se repetem com maior

\footnotetext{
${ }^{8}$ Excerto original: “(1) finalism, a neo-Aristotelian functionalism based on inherent teleology, (2) adaptionism, an evolutionary functionalism in a Darwinian tradition, (3) classical (Durkheimian) functionalism, explaining institutions through their usefulness for society, (4) instrumentalism, a normative theory of using law for social engineering, (5) refined functionalism, a functionalist method that replaces certain postulates of classical functionalism with empirically testable hypotheses, (6) epistemological functionalism, an epistemology that focuses on functional relations rather than on the ontology of things, and (7) equivalence functionalism, building on these concepts but emphasizing the non-teleological, non-causal aspect of functional relations". Para uma explicação específica e exaustiva de cada uma destas correntes se sugere consultar o artigo supracitado nesta nota.
}

BRENER, Paula; COLOMBI, Henri; RAMOS, Marcelo Maciel. OS MÉTODOS DO DIREITO COMPARADO: POR UM PLURALISMO METODOLÓGICO E UM COMPARATIVISMO CRÍTICO. Revista Acadêmica da Faculdade de Direito do Recife ISSN: 2448-2307, v. $\quad$ 93, n.1, p.212-226 Abr. 2021. ISSN 2448-2307. <Disponível em: ISSN: 2448-2307, v. 93, n.1, p.212-226 Abr
https://periodicos.ufpe.br/revistas/ACADEMICA/article/view/249545> 


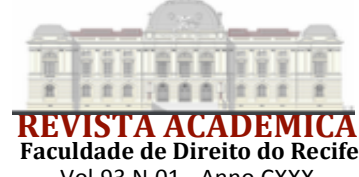

Vol.93 N.01 - Anno CXXX

frequencia (Ibid, p. 342). O primeiro deles é a busca, na comparação de duas normas de contextos sociais distintos, de uma qualidade comum a ambas. Como são normas diferentes em suas formas e justificativas, é na função que normalmente se afirma ser possível identificar esse elemento comum, denominado de tertium comparationis, isto é, a terceira parte da comparação (JANSEN, 2006, p. 310). Entendia-se - e essa ainda é uma percepção comum entre comparatistas - que o modo de se comparar instituições de tradições jurídicas distintas seria buscando aquilo que elas apresentam de semelhante. E o semelhante era normalmente identificado na função que em contextos distintos se atribuia a diferentes tipos de normas (ZWEIGERT; KÖTZ, 1998, p. 34).

É importante ressaltar que uma mesma função ou tarefa, que em um dado ordenamento se atribui a certo instituto ou instituição, em outro poderá ser desempenhado por um mecanismo ou autoridade diversos. Um exemplo muito conhecido é a função ordenadora do direito. Enquanto na tradição romano-germânica esta é exercida na forma da norma legislada, na tradição jurídica do common law, essa função compete ao judiciário pela formação vinculativa de precedentes (DAVID, 2002, p.381-382).

Além disso, as compreensões e explicações tradicionais ou doutrinárias sobre certo instituto normativo ou instituição podem variar enormemente, mesclar elementos legais e extralegais ou se basear inteiramente nestes últimos e, mesmo assim, desempenharem funções correspondentes (MICHAELS, 2006, p. 342). Em termos mais concretos, uma função que em determinado ordenamento jurídico é desempenhada por uma lei pode estar presente em outro sob a forma de costume, de elaboração teórica dos juristas ou de construção jurisprudencial.

O segundo elemento que se observa com frequência no funcionalismo reside no fato de ele não concentrar suas análises simplesmente nas normas legais ou institucionalmente estabelecidas, mas de incluir também outros elementos para além do direito formal ou oficial. Portanto, os trabalhos funcionalistas de Direito Comparado são estudos factuais, que geralmente abordam decisões judiciais, os argumentos utilizados pelos advogados na prática quotidiana, a doutrina, além de outros elementos culturais que estão para além da materialidade da norma posta (REITZ, 1998, p. 628).

O terceiro elemento mais recorrente do método funcionalista consiste na contextualização socio-cultural da função das normas examinadas. Entende-se que se deve buscar a relação da função da norma com a sociedade na qual ela está inserida. Conforme afirma Reitz, "um profundo conhecimento da história do país, de seu povo e de suas tradições filosóficas e religiosas é necessário para compreender as formas locais de raciocínio jurídico e de julgamentos de valor" (Ibid, p. 632, tradução nossa) ${ }^{9}$.

Apesar de o funcionalismo ocupar-se do contexto social da norma, ele o faz mantendo uma divisão clara entre o direito e a sociedade (MICHAELS, 2006, p. 342). Ele adimite a relação que existe entre eles, mas entende que não se deve perder de vista que seu objetivo central é analisar o direito e não a sociedade (SAMUEL, 2014, p. 79-81). Os conhecimentos históricos, filosóficos e socio-culturaisusados para a compreensão da função da norma acabam servindo apenas como aporte introdutório, muitas vezes apresentados de modo apressado, protocolar e superficial.

Jaakko Husa critica o pequeno espaço que a relação entre a função e o contexto tem nas pesquisas que se utilizam do método funcional (HUSA, 2007). Os funcionalistas observam o contexto apenas de forma breve. Eles estão mais preocupados em observar e compreender a vigência e a eficácia da função da norma em análise. Ao fazer um exame contextual superficial e breve, perde-se de vista a complexidade cultural e linguística que engendra as cadeias de significados que uma norma comunica em determinado contexto. Além disso, é muito comum

${ }^{9}$ Excerto original: "In-depth knowledge of the history of the country and its peoples and its philosophical and religious traditions is necessary to understand the indigenous forms of legal reasoning and value judgments". 
que o comparatista funcionalista não esteja devidamente atento para as distorções e projeções de sentidos que uma análise apressada de normas de contextos diferentesproduz.

Embora menos difundido, poderíamos apontar ainda um quarto elemento do funcionalismo $^{10}$. Trata-se do juízo valorativo da função. A ideia é que, a partir do estudo comparado de diferentes instituições jurídicas, fosse possível avaliar qual seria a que desempenha melhor a função que lhe fora atribuída (MICHAELS, 2006, p. 342). Ou, ainda, que, a partir da observação dediferentes soluções normativas, fosse possível derivar uma proposiçãoinovadora, capaz de desempenhar a função desejada com mais eficiência e eficicácia (ZWEIGERT; KÖTZ, 1998, p. 47).

Embora possa apresentar-se sob diferentes formas, de um modo geral pode-se dizer que o funcionalismo parece melhor vocacionado para estudos de microcomparação, aqueles que abordam "instituições ou problemas jurídicos específicos, ou seja, as normas utilizadas para resolver problemas reais ou conflitos de interesses particulares" (Ibid, p. 05). Em razão da superficialidade de seus exames, o método funcionalista estaria menos apto a promover uma abordagem crítica acerca das regras e instituições analisadas. Husa entende essa limitação como uma contrapartida inevitável para se poder empreender uma comparação que trate cada solução encontrada para um mesmo problema de maneira igualmente válida.

Uma vez que o funcionalismo se adéqua à análise comparativa de normas e de instituições jurídicas específicas, ele se mostra de pouca valia para a análise de famílias legais, mentalidades ou culturas jurídicas ${ }^{11}$. Sua deficiência em considerar os aspectos culturais envolvidos na realidade do direito reduz ainda mais o campo de atuação do método funcionalista. Ele é, enfim, pouco útil quando se deseja traçar comparações entre ordens jurídicas que apresentam diferenças acentuadas do ponto de vista da cultura ${ }^{12}$.

Compreendido o método por suas características e por seu rendimetno prático, é importante chamar atenção para as críticas que nas últimas décadas têm sido levantadas contra as limitações do método funcionalista ${ }^{13}$. De início, ele é criticado por sua tendência homogeneizadora. Em seu ímpeto pragmático de compatibilização de diferentes ordenamentos jurídicos, ele acaba por revelar sua agenda (geralmente não declarada) de "civilizar" ordenamentos supostamente menos avançados. Além disso, ele é criticado por ser utilizado normalmente como método único e, portanto, insuficiente para comparação de direitos ${ }^{14}$, o que acaba conduzindo a um exame superficial, supostamente técnico, mas que deixa escapar muito da complexidade dos aspectos culturais e sociais da norma.

Critica-se, ainda, o excessivo valor que o funcionalismo confere à busca de semelhanças, as quais são muitas vezes presumidas apressadamente, encobrindo, dessa maneira, as peculiaridades da cultura normativa em exame ${ }^{15}$. Por fim, ele é criticado por afirmar como parti prisa neutralidade de seus critérios de avaliação e classificação das normas comparadas (FRANKENBERG, 1985, p. 415 et seq.). Na crença cega de que seus valores, categorias e métodos estariam fundados em uma razão supostamente universal, ele oculta toda parcialidade linguística, discursiva e axiológica que marca as produções normativas, as suas e as dos outros.

\footnotetext{
${ }^{10}$ Entre os que adotam a função como elemento valorativo se incluem: Zweigert e Kötz(1998, p.47); Reitz (1998, p. 635). Dentre os que rejeitam: Jaakko Husa (2009).

${ }^{11}$ Cf.JaakkoHusa (2003, p. 8) e Geoffrey Samuel (2014, p.79-81).

${ }^{12}$ Nesse sentido, em sua análise acerca do Controle de Constitucionalidade nos países nórdicos Husa transparece sua convicção de ser o método funcionalista mais adequado e de mais fácil aplicação em contextos de proximidade cultural entre as ordens comparadas ao dizer que é apropriado o método comparativo funcionalista por serem as ordens em análise próximas do ponto de vista da cultura jurídica(2000).

13 Notadamente a Teoria Crítica do Direito Comparado de Frankenberg(1985) e a proposição metodológica Hermenêutica ou Contextualista de Pierre Legrand (1999).

${ }^{14}$ Conforme se percebe na postura assumida por Zweigert e Kötz no excerto: "o princípio básico de todo direito comparado é o da funcionalidade"(1998, p.34, tradução nossa).

${ }^{15}$ Cf.GünterFrankenberg (1985, p. 436-437) e Pierre Legrand (2003, p.249).
}

BRENER, Paula; COLOMBI, Henri; RAMOS, Marcelo Maciel. OS MÉTODOS DO DIREITO COMPARADO: POR UM PLURALISMO METODOLÓGICO E UM COMPARATIVISMO CRÍTICO. Revista Acadêmica da Faculdade de Direito do Recife ISSN: 2448-2307, v. 93, n.1, p.212-226 Abr. 2021. ISSN 2448-2307. <Disponível em: ISSN: 2448-2307, v. 93, n.1, p.212-226 Abr
https://periodicos.ufpe.br/revistas/ACADEMICA/article/view/249545> 
Ciente dos problemas do método, mas ainda convencido de sua adequabilidade, Jaakko Husa propõe uma "versão moderada do funcionalismo" (HUSA, 2003, p. 2). Essa nova perspectiva é apresentada como uma posição tolerante que identifica as limitações inerentes ao método e que procura corrigi-las com o aporte de novas metodologias. Inicialmente, a versão moderada do funcionalismo não se concebe como método hegemônico, útil para toda e qualquer forma de comparação. Ao contrário, reconhece o valor dos outros métodos, tomando o funcionalismo apenas como mais uma das ferramentas metodológicas para se empreender um estudo comparado (HUSA, p. 23-24). Defende Husa que o comparatista deve sempre fazer um juízo de adequabilidade do método à pesquisa a ser empreendida (HUSA, p. 17).

Além disso, note-se que a presunção de similitude (praesumptio similitudinis), verdadeiro axioma do funcionalismo clássico ${ }^{16}$, não encontra espaço na vertente moderada. Preza-se igualmente pelas diferenças e pelas semelhanças existentes entre as ordens jurídicas que são objetos da investigação. A ideia é que não se deve partir da presunção de existência de semelhanças necessárias (supostamente ocultas ou não evidentes) entre as funções das normas em exame. Como ferramenta de investigação que é, o método deve estar pronto para identificar, da mesma forma, diferenças ou semelhanças (HUSA, 2003, p. 20).

Por fim, Husa não busca justificar a presunção de neutralidade do funcionalismo. Ele admite que o método tem pouco a contribuir quando se trata de analisar como o pensamento hegemônico ocidental orienta a abordagem do direito comparado em prol de seus interesse. Para ele, o método funcionalista responde à pergunta acerca de "como comparar", mas não diz o "porquê de se comparar" (HUSA, p. 19). Por essa razão, o papel das teorias críticas do Direito Comparado torna-se especialmente relevante.

Em um contexto de globalização econômica e multiculturalismo, uma pesquisa em Direito Comparado que se utilize do método funcionalista não pode incorrer nos mesmos preconceitos cultivados pelos comparatistas clássicos. Face às suas reconhecidas limitações, presentes mesmo em sua forma mais atualizada, não se pode dispensar uma abordagem crítica não só do objeto comparado, mas do próprio método. Respostas acerca dos motivos de se comparar, esclarecimentos acerca dos interesses aos quais o estudo empreendido serve, os elementos culturais envolvidos, e mesmo a influência da subjetividade do estudioso na percepção da normatividade estrangeira são de extrema importância, ainda que no nível da microcomparação.

\section{O MÉTODO ESTRUTURALISTA}

O método estruturalista procura compreender e comparar as normas de diferentes sociedades, tomando-as enquanto modelos normativos, os quais tornam manifestas as estruturas jurídicas, as conscientes $\mathrm{e}$ as inconscientes. Ele parte das categorias desenvolvidas pelo sociólogo Claude Lévi-Strauss, para quem "a noção de estrutura social não remete à realidade empírica, e sim aos modelos construídos a partir dela" (LÉVI-STRAUSS, 2008, p. 301) ${ }^{17}$. Explica Lévi-Strauss que a estrutura social "apresenta um caráter de sistema", de modo que a modificação de um de seus elementos implica na modificação de todos os demais. Destarte, a estrutura social não é o conjunto das relações observáveis em cada sociedade, mas manifesta um modelo abstrato capaz de dar conta de todos os fatos observados (LÉVI-STRAUSS, p. 400-401).

\footnotetext{
${ }^{16}$ Conforme expressamente se demonstra na clássica obra de Introdução ao Direito Comparado de Konrad Zweigert e Hein Kötz (1998,p.40).

${ }^{17}$ Explicita o antropólogo Lévi-Strauss de forma inafastável a diferença entre relações sociais e estruturas sociais, afirmando as primeiras enquanto componentes integrantes dos modelos que expõem a estrutura e aos quais ela remete. Vale dizer, ainda, que o autor não entende as normas culturais (dentre as quais se incluem as normas jurídicas) como estruturas, mas como peças importantes para se descubrir as estruturas sociais (2008, p. 405).
} 
O método estruturalista, assimilado por juristas comparatistas, defende que o estudo de diferentes ordenamentos jurídicos deve ser feito a partir da observação e oposição de elementos que em conjunto formam um sistema ${ }^{18}$. Deve-se buscar a estrutura intrínseca do modelo observado, a qual muitas vezes se oculta nas variadas formas observáveis de relações normativas. A realização de um estudo nos moldes estruturalistas precisa levar em conta alguns requisitos tanto para a análise dos fatos quanto para a composição de um modelo. Quanto à investigação da realidade, Lévi-Strauss afirma a necessidade de se observar e de se descrever todos os fatos, afastando as influências subjetivas e pressupostos teóricos. O autor exige, ainda, que o estudo dos fatos seja realizado tanto em si mesmo quanto em relação ao seu conjunto.

No que concerne aos requisitos para a composição de um modelo, afirma o antropólogo que tais sistemas devem envolver, primeiramente, todos os fatos observados. "A busca de estruturas intervém num segundo estágio, quando, depois de termos observado o que existe, tentamos extrair dái os únicos elementos estáveis - e sempre parciais - que permitem comparar e classificar" (2008, p. 463). Exige-se também que os modelos construídos a partir da observação operem enquanto correspondentes a determinada categoria que integra um grupo de transformações. Por fim, ressalta-se o caráter sistemático da estrutura cuja alteração de qualquer de seus elementos acaba por transformá-la e alterá-la como um todo ${ }^{19}$.

Vale dizer que o método estruturalista obteve especial acolhida entre os estudiosos do direito privado, mais familiarizados com o modelo idealizado por Gaio, o qual revela uma teoria das relações sociais que toma como base constitutiva da lei a lógica estrutural do vínculo jurídico entre pessoas, coisas e ações ${ }^{20}$. O modelo desenvolvido pelo jurisconsulto romano apresenta diversas categorias de forma taxonômica, ou seja, divide-se e subdivide-se em partes reduzidas (categoria, subcategoria etc) a partir da interrelação entre esses três elementos básicos do direito.

No âmbito da Teoria do Direito, a mais difundida construção estruturalista é a de Hans Kelsen. O sistema criado pelo jusfilósofo austríaco tem como ponto central para a compreensão do Direito o conceito de validade da norma jurídica. Uma norma somente é considerada válida caso esteja em conformidade com a norma imediatamente superior e tenha sido criada pela autoridade competente para executar este ato. Essa validação das normas conforma um sistema piramidal que culmina na última das normas, aquela superior a todas as demais e que a todas confere fechamento lógico, a Grundnorm - norma fundamental - (1998). Esse sistema consiste em uma criação abstrata que visa tornar explicita a fronteira entre a norma de direito e os outros tipos normativos. Expõe uma estrutura de normas per seas quais têm a si mesmas como fundamento de legitimidade.

Em se tratando do Direito Comparado, é função do comparatista que opta por esse esquema estabelecer a matriz, o código estrutural do sistema legal em estudo, diferenciando-o das demais estruturas observáveis, aquelas não jurídicas. O pesquisador deve também identificar as características elementares do complexo normativo estrangeiro, para então compará-las com outro, em geral aquele de origem do pesquisador. Conforme Lévi-Strauss: "[a] tarefa do estruturalista é identificar e isolar os níveis de realidade que possuem um valor estratégico a partir da perspectiva em que ele se coloca, isto é, que podem ser representados na forma de modelos, qualquer que seja a natureza destes últimos" (LÉVI-STRAUSS, 2008, p. 307).

René David, cuja obra representa um divisor de águas no desenvolvimento do Direito Comparado, adota o estruturalismo como método central de suas investigações. O autor constrói seu trabalho a partir da sistematização e comparação das estruturas normativas hegemônicas em determinados contextos culturais. Ele denomina essas estruturas de grandes sistemas jurídicos ou famílias de direitos, as quais identifica como Direito Romano-Germânico, Direito da Common

\footnotetext{
${ }^{18}$ Define Geoffrey Samuel o conceito de sistema como "estrutura conceitual a qual não é apenas descritiva, mas, na verdade, criativa, ele produz novos elementos em si mesmo" (SAMUEL, 2014, p. 98,tradução nossa).

${ }^{19}$ Concorda com esse último preceito Geoffrey Samuel (2014).

${ }^{20}$ I. 1,8 .
}

BRENER, Paula; COLOMBI, Henri; RAMOS, Marcelo Maciel. OS MÉTODOS DO DIREITO COMPARADO: POR UM PLURALISMO METODOLÓGICO E UM COMPARATIVISMO CRÍTICO. Revista Acadêmica da Faculdade de Direito do Recife ISSN: 2448-2307, v. 93, n.1, p.212-226 Abr. 2021. ISSN 2448-2307. <Disponível em: https://periodicos.ufpe.br/revistas/ACADEMICA/article/view/249545> 


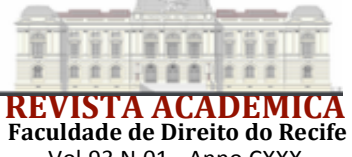

Vol.93 N.01 - Anno CXXX

Law, Direito dos países Socialistas, Direito Mulçulmano, Direito Hindu, Direitos do Extremooriente etc $^{21}$. Embora não rejeite completamente o funcionalismo, René David atribui maior importância aos conceitos e categorias que ordenam as normas em seu interior. Afinal, "[c]ada direito constitui de fato um sistema. Emprega um certo vocabulário, corresponde a certos conceitos, agrupa as regras em certas categorias, comporta o uso de certas técnicas para formular regras e certos métodos para interpretar (...)" (2002, p. 20); ou seja, possui peculiaridades que lhe caracterizam enquanto estrutura.

Contudo, o estruturalismo não está isento de contradições e não é imune a críticas quando da sua aplicação ao Direito Comparado. A primeira delas consiste no problema de se comparar estruturas que não necessariamente possuem compatibilidade ou alguma equivalência. Essas inconsistências têm início no momento da própria descrição e tradução das diferenças conceituais, normativas, políticas ou culturais.

Um exemplo interessante está na Constituição Chinesa de 1982 que em seu primeiro artigo define paradoxalmente ser a República Popular da China "um Estado socialista subordinado à ditadura democrático-popular da classe operária". Tal forma de governo não seria possível pela adoção dos conceitos utilizados pela ótica do Ocidente. Há, do pondo de vista das redes de significados ocidentais, uma incompatibilidade entre os termos ditadura e democracia.

Uma segunda dificuldade do estruturalismo aplicado ao Direito Comparado se encontra na premissa de que a investigação deve ser realizada de forma objetiva e não enviesada. Trata-se de uma ficção amplamente alimentada pelas perspectivas racionalistas sobre as quais se estruturou o Direito no Ocidente. Esse mito da neutralidade e objetividade encombre o fato de que, de modo inconsciente e despercebido, um indivíduo tende a projetar em sua análise elementos de seu próprio sistema cultural e normativo que não existem de fato no contexto do objeto estudado.

Note-se que, quando assimilado pelas perspectivas da ciência jurídica, o caráter abstrato das estruturas, enquanto chave de explicação de um dado contexto social, acaba sendo inserindo em um quadro de expectativas radicalmente universalistas ou universalizantes, que desconsidera ou que obscurece as peculiaridades não só dos fatos e normas observáveis, mas dos modelos que cada contexto social constrói a partir deles e, sobretudo, da singularidade das estruturas sociais (e normativas) que esses modelos revelam.

Nada obstante, o método estruturalista, quando cioso de seus limites e seus perigos, é certamente útil no esforço de compreensão dos elementos ocultos pela lógica interna de um complexo normativo, bem como para a comparação de quadros normativos mais ampliados, o que envolve uma construção de modelos para além da simples descrição das normas, capazes não só de traduzir, mas de organizá-los em esquemas mais abrangentes e comporáveis. Afinal, conforme Lévi-Strauss: "[a]s investigações estruturais não apresentariam nenhum interesse se as estruturas não fossem traduzíveis em modelos cujas propriedades formais sejam comparáveis, independentemente dos elementos que os compõem" (2008, p. 307).

\section{O MÉTODO HERMENÊUTICO}

O método hermenêutico tem como preocupação central a busca pelo significado do texto da norma no contexto sociocultural em que ele está inserido. Texto é aqui compreendido como

\footnotetext{
${ }^{21}$ Interessante destacar em nota que outros autores trabalham com diferentes sistemas. Nesse sentido, contemporaneamente, ganha relevo o modelo sulamericano, que passa a ser identificado como sistema autonomo,caracterizado por um forte ecletismo jurídico e cujas manifestações de direito não temprecedentes no continente. Veja-se, por exemplo, a posição de Hernández-Bretón: "[e]l resultado de tal mezcla es un mosaico de muy diversos sistemas jurídicos que, aun cuando pueden ubicarse en el circulo o familia del Civil Law, presentan un especial matiz con propias y particulares características".(1998, p.40). Para maiores aprofudamentos, cf. ANDRADE; PEREIRA; FERREIRA, 2018.
}

BRENER, Paula; COLOMBI, Henri; RAMOS, Marcelo Maciel. OS MÉTODOS DO DIREITO COMPARADO: POR UM PLURALISMO METODOLÓGICO E UM COMPARATIVISMO CRÍTICO. Revista Acadêmica da Faculdade de Direito do Recife ISSN: 2448-2307, v. 93, n.1, p.212-226 Abr. 2021. ISSN 2448-2307. <Disponível em: ISSN: 2448-2307, $\quad$ v. 93, n.1, p.212-226 Abr.
https://periodicos.ufpe.br/revistas/ACADEMICA/article/view/249545> 


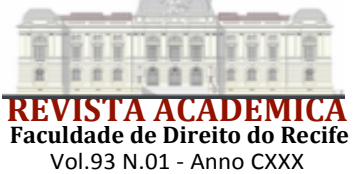

unidade de sentido e não apenas como fragmento escrito. A sua compreensão só seria plena na medida em que se pudesse decodificar os significados produzidos no contexto de sua criação, interpretação e aplicação. O contexto é entendido como o conjunto de condições socio-históricas, os saberes, as ideias, os valores e os comportamentos que permeiam o universo do direito (LEGRAND, 1999, p. 16). Dessa forma, para o método hermenêutico, os textos legais são tidos como significantes a serem decifrados, que devem ser compreendidos enquanto situados dentro de um momento histórico e realidade próprios (LEGRAND, p. 17).

O maior expoente dessa corrente é Pierre Legrand, que propõe uma comparação que busque identificar as diferenças no lugar de apenas supor ou mesmo forjar as semelhanças entre os ordenamentos jurídicos (LEGRAND, 2003, p. 271-272). Essa concepção é inovadora no âmbito do Direito Comparado que,historicamente, se concentrou na missão de identificar(ou produzir) as semelhanças dos diferentes sistemas normativos examinados.

A praesumptio similitudinis, isto é, a presunção de semelhança do funcionalismo clássico é a manifestação no Direito Comparado da pretensão universalista que perpassa boa parte do pensamento ocidental. Presume-se a semelhança a partir da crença de que determinadas questões são postas para todo e qualquer ordenamento e, diante delas, deduz-se regulamentações comuns que busquem solucioná-las de modo equivalente. Não obstante se admita que a solução normativa possa por vezes ser encontrada para além das leis em circunstâncias socioculturais diversas, o funcionalismo clássico presume que ela sempre estará presente, pois se imagina uma disciplina de fundo comum derivada de uma suposta racionalidade universal.

A rejeição pelo método hermenêutico desta presunção de semelhança decorre da incorporação de certas perspectivas críticas e relativistas desenvolvidas pelas ciências sociais nas últimas décadas, as quais passaram chamar atenção para as originalidades e singularidades das construções culturais produzidas em contextos linguísticos e semânticos diferentes. Essas novas perspectivas denunciam as pretensões universalizantes hegemônicas no Ocidente, as quais se revestem de uma neutralidade supostamente em favor do pluralismo cultural e da liberdade, mas que acabam por classificar e hierarquizar as construções culturais alheias no quadro de valores e categorias que são muitas vezes estranhos à cultura objeto do exame e da comparação.

Ao recusar as hierarquizações falsamente neutras das culturasestrangeiras, o método hermenêutico passa a atribuir um igual valor à diferença. Ele entende que a diversidade deva ser respeitada independentemente da estranheza que provoque à visão do comparatista, ou do quão inapropriadas pareçam suas lógicas internas próprias. Sustenta-se que a especificidade dos contextos justifica as peculiaridades presentes nos ordenamentos dos outros. Deste modo, cada determinação normativa, por mais absurda que pareça, deve ser compreendida (ou ao menos interpretada) dentro do quadro de valores e significados próprios de uma dada sociedade.

Para a perspectiva hermenêutica, a cultura está no centro da investigação comparatista. Partindo dessa proposta, buscam-se os sentidos que devem ser extraídos dos textos jurídicos à luz das visões de mundo que permeiam a sociedade que eles regem. Jaakko Husa entende que o método hermenêutico, que ele denomina contextualismo, não é uma perspectiva metodológica totalmente diferente do funcionalismo. Seria na verdade um mesmo método que passa então a conferir maior e mais justo valor à inserção e compreensão do contexto (2007). De todo modo, vale o alerta de que, uma vez que o funcionalismo tende a se confundir com o próprio desenvolvimento do Direito Comparado, os outros métodos tendem a ser vistos mais como complementos ou atualizações do método funcional do que como uma renovação radical do modo de se realizar a comparação.

Uma das inovações do método hermenêutico está no reconhecimento da impossibilidade de se desconsiderar a relação entre os objetos de estudo e seus respectivos observadores. Diante disso, procura-se compreender os fatos em análise levando em conta os processos psicológicos e histórico-culturais que envolvem o estudo do ponto de vista daquele que o empreende. 
Para Legrand, tanto o intérprete quanto o texto investigado estão inseridos em contextos e, em se tratando de direitos a comparar, eles serão necessariamente diferentes. Esse fator impossibilita uma interpretação inteiramente objetiva (LEGRAND, 2003, p. 286). Isto porque o comparatista não é capaz de se desvincular completamente de seus próprios preconceitos, categorias e valores no momento de realização da análise (LEGRAND, p. 255-256).

Além disso, o próprio elemento linguístico, necessário para a compreensão e comparação de normas em contextos culturais distintos, está inserido em uma rede de significados particulares de uma cultura e época, os quais, muitas vezes, chegam inevitavelmente distorcidos à compreensão do comparatista. Apesar da separação dos contextos nos quais estão inseridos o objeto e o observador, acredita-se poder atingir a compreensão da realidade jurídica estudada, ainda que imbuída de subjetividade e distorção $(I d, 1999$, p. 17). Vale aqui lembrar da lição de Hans-Georg Gadamer, para quem:

O sentido da lei que se apresenta em sua aplicação normativa, não é, em princípio, diferente do sentido de um tema, que ganha validez na compreensão de um texto. É completamente errôneo fundamentar a possibilidade de compreender textos na pressuposição da congenialidade que uniria o criador e o interprete de uma obra. [...] O milagre da compreensão consiste, antes, no fato de que não é necessária a congenialidade para reconhecer o que é verdadeiramente significativo e o sentido originário de uma tradição (GADAMER ,1999, p. 464).

Desta forma, aquele que realiza um estudo em Direito Comparado utitizando-se do método hermenêutico é, nas palavras de Legrand, "um intérprete que busca entender, dentro do entrelaçamento com seu próprio mundo jurídico, um outro direito e uma outra maneira de viver dentro do direito percebido na realidade do outro" (LEGRAND, 1999, p. 16, tradução nossa $)^{22}$.Nesse sentido, o papel do comparatista defendido por Legrand é o de avançar em direção a um outro nível de interpretação do Direito Comparado. Um estudo baseado no método hermenêutico procura decodificar os significantes presentes no direito do outro e transcrevê-lo em linguagem compreensível àqueles que possuem interesse em conhecê-lo.

A tarefa de explicar as normas que regulam uma dada sociedade, utilizando-se de uma linguagem que não lhe é própria, implicará sempre em uma descrição aproximada (muitas vezes distorcida) das normas observadas. Afinal, a explicação depende de um processo prévio de tradução, no qual os termos empregados nunca serão absolutamente precisos para descrever a realidade do outro e carregarão invariavelmente elementos semânticos e culturais que são próprios daqueles que promovem a comparação (LEGRAND, 2003, p. 290-291) ${ }^{23}$.

Um exemplo do problema no trato linguístico no exercício do Direito Comparado pode ser observado no transplante legal da willful blindness doctrine na forma da ignorância deliberada para o Direito Penal brasileiro. O instituto de origens na tradição jurídica do common law ganhou expressão no Brasil a partir da atividade jurisprudencial, a qual se fundamentou em artigo, posteriormente convertido em obra, no qual foram identificados erros na tradução de precedentes chave para a compreensão do instituto no direito penal norte-americano.

Assim, identifica-se nas obras e decisões do então Juiz Sergio Fernando Moro a inserção do requisito da "indiferença" em precedentes judicias norte-americanos, nos quais o termo inexiste $^{24}$. Não apenas a "indiferença" não encontra respaldo na regra do common law, mas é

\footnotetext{
${ }^{22}$ No original:“C'est um interprète qui cherche à entendre dans leur entrelacement avec son propre monde juridique, un autre droit et une autre façon de vivre dans le droit aperçus chez altrui".

${ }^{23}$ De modo similar, JeanPradel (1995, p. 38).

${ }^{24}$ Lucchesi (2018, p. 155) aponta para a errônea tradução por Moro de julgados norte-americanos, o qual teria inserido em seus trabalhos elemento inexistente em referidos julgados, a indiferença (MORO, 2010. p. 71). Esse problema de tradução acabaria por se manifestar em grande número de julgados no Brasil, reproduzindo o
} 


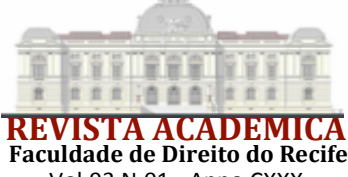

Vol.93 N.01 - Anno CXXX

também expressamente debatida e refutada por suas cortes, como nas discussões do caso GlobalTech Appliances INC. vs. SEB S.A. (2011), leading case em matéria civil que revisitou o debate sobre a ignorância deliberada julgado pela Suprema Corte norte-americaa ${ }^{25}$. Essa incorreção pode a princípio parecer simples, mas possui graves repercussões penais, as quais, contudo, não cabe apontar no limitado espaço deste trabalho ${ }^{26}$.

$\mathrm{Na}$ perspectiva do método hermenêutico, o comparatista deve estar consciente do fato de que sua compreensão do significado do ordenamento estrangeiro será sempre uma construção que se dá na conjunção dos contextos que forma a si e ao seu objeto ${ }^{27}$. Como já dito, não há como pensar uma análise hermenêutica desvinculada do observador. Por influir diretamente nos resultados, o sujeito observador deve estar tão bem compreendido quanto o próprio objeto observado. Roy Wagner afirma, a propósito da semelhante tarefa comparatista do antropólogo, que ele "é obrigado a incluir a si mesmo e seu próprio modo de vida em seu objeto de estudo, e investigar a si mesmo" (WAGNER, 2012, p. 39). Isto porque o antropólogo experimenta e compreende o seu objeto de estudo (a cultura do outro) através do universo dos seus próprios significados. Sua análise nunca será absolutamente objetiva. O viés cultural com que se compreende o mundo já está posto em sua constituição enquanto sujeito de cultura, nas possibilidades de suas construções linguísticas e científicas. $O$ mesmo vale parao jurista comparatista.

Pierre Legrand apresenta um exemplo simples para explicar essa perspectiva. Ele adota o ponto de vista do jurista francês, portanto, o seu ponto de vista pessoal. O objeto a ser estudado é o Common Law inglês. O comparatista deverá reconhecer inicialmente as características de seu próprio ordenamento, a filosofia, a história que o permeia e que se expressa na sociedade na qual ele se insere desde as peculiaridades mais triviais até os aspectos mais importantes. O pensamento francês, defende Legrand, é nomotético, acostumado a proposições lógicas, gerais. Essa característica obviamente se reflete em seu direito, que se organiza em codificações que buscam exaurir temas e prever todas as questões e soluções de modo a priori. A tendência à logicidade é entrevista de outras formas, muito distantes do direito, como, por exemplo, no paisagismo. A organização dos jardins franceses é geométrica, proporcional, refletindo uma harmonia regrada e rígida que "traduziria o absolutismo monárquico que pretendia comandar mesmo a natureza" (LEGRAND, 1999, p. 8).

Enquanto isso, ao voltar os olhos ao ordenamento do outro que é objeto do estudo comparatista, o pesquisador deve buscar construir sua própria compreensão acerca da maneira como aquele se constitui. Assim, por exemplo, o sistema inglês, marcado pelo utilitarismo, conforme visto pelos olhos de um francês, pode apresentar-se como mais pragmático e empírico. Em oposição ao estilo nomotético do pensamento francês, os ingleses seriam idiográficos. Seu direito buscaria alcançar as respostas às questões à medida que estas surgem, adequando a cada

entendimento do autor. Assim, por exemplo, a definição da teoria apresentada pelo no julgamento da ação penal 470 - Mensalão - no Supremo Tribunal Federal: "Para configuração da cegueira deliberada em crimes de lavagem de dinheiro, as Cortes norte-americanas têm exigido, em regra, (i) a ciência do agente quanto à elevada probabilidade de que os bens, direitos ou valores envolvidos provenham de crime, (ii) o atuar de forma indiferente do agente a esse conhecimento, e (iii) a escolha deliberada do agente em permanecer ignorante a respeito de todos os fatos, quando possível a alternativa”. BRASIL. STF. Tribunal Pleno. Embargos infringentes na AP 470. Brasília. Julgamento em 13/03/2014. No mesmo sentido: BRASIL. TRF1. Terceira Turma. Habeas Corpus n. 0028761-80.2017.4.01.0000. Brasília.Julgadoem 27/07/2017.Publicadoem e-DJF1 04/08/2017.

${ }^{25} \mathrm{Cf}$. "2. Deliberate indifference to a known risk that a patent exists does not satisfy the knowledge required by $\S 271(b)$.".ESTADOS UNIDOS DA AMÉRICA. Suprema Corte dos Estados Unidos. Global-tech appliances, INC. v. SEB S.A. 563 U.S. maio de 2011.

${ }_{26}$ Para maior aprofundamento, confira-se a obra de Guilherme Lucchesi (2018, p. 155).

${ }^{27}$ Nesse sentido também se posiciona Gadamer acerca do método hermenêutico ao afirmar que o "papel do interprete não é apenas o de reproduzir, mas o de fazer a opinião daquele assim como lhe pareça necessário.” (1999, p.460, tradução livre).

BRENER, Paula; COLOMBI, Henri; RAMOS, Marcelo Maciel. OS MÉTODOS DO DIREITO COMPARADO: POR UM PLURALISMO METODOLÓGICO E UM COMPARATIVISMO CRÍTICO. Revista Acadêmica da Faculdade de Direito do Recife ISSN: 2448-2307, v. 93, n.1, p.212-226 Abr. 2021. ISSN 2448-2307. <Disponível em: ISSN: 2448-2307, v. 93, n.1, p.212-226 Abr
https://periodicos.ufpe.br/revistas/ACADEMICA/article/view/249545> 
caso particular a melhor solução possível e consolidando um exemplo para orientar as futuras decisões.

A proposta contextualista do método hermenêutico, decerto, mostra-se interessante por permitir a incorporação de um juízo crítico sobre a própria limitação do presquisador relativamente ao seu horizonte interpretativo e abrir a investigação comparativa ao pluralismo cultural e ao relativismo moral. Contudo, como qualquer metodologia de Direito Comparado, o contextualismo detém seus pontos fracos. Conforme destaca Husa, a proposta hermenêutica de Legrand encontra-se muito centrada nas advertências acerca dos riscos da generalização e da nociva tendência de universalização derivada do contexto cultural em que o pesquisador está inserido, mas pouco oferece em termos de ferramentas concretas para se empreender um trabalho comparativo. Nas palavras do autor, a proposta de Legrand estaria mais em discutir o "por que de se comparar" do que o "como se comparar" (HUSA, 2003, p.19-20).

A essa crítica pode-se somar uma outra, sobremaneira pertinente ao contexto acadêmico brasileiro. A necessidade de imersão cultural, compreensão profunda em termos de linguagem e substrato filosófico e teórico a permear a cultura de origem e a cultura do ordenamento a ser comparado, levada às últimas consequências, podem inviabilizar uma pesquisa comparativa. De certo que, tendencialemente, quanto mais profunda a imersão e mais amplo o conhecimento melhores serão os resultados. Contudo, em um contexto de escassez de recursos e mesmo de limitações decorrentes de tempo de pesquisa, experiências prévias, não parece adequado um veredito pela impossibilidade de qualquer empreitada comparativa em razão de limitações de horizontes hermenêuticos. Nesse contexto, a proposta contextualista serve antes como uma advertência, um chamado à reflexão, do que um real pressuposto a toda e qualquer comparação.

\section{CONCLUSÕES}

Frente às diferentes qualidades e limitações dos métodos de Direito Comparado que foram até aqui expostos, bem como aos variados objetivos que uma pesquisa comparatista pode ter, seria pouco produtivo propor a adoção generalizada de um único método. Não há dúvidas de que abordagens distintas exigem caminhos diversos, mas a utilização de apenas um método de forma rígida e exclusiva pode conduzir a resultados limitados, pouco consciêntes e críticos em relação as suas próprias deficiências.

O pluralismo metodológico parece-nos a chave para uma comparação crítica, capaz de produzir uma compreensão ao mesmo tempo abrangente e profunda do objeto comparado. A adoção de diferentes métodos bem definidos e compatibilizados entre si parece-nos o caminho ideal para uma pesquisa bem estruturada e confiável em Direito Comparado. É claro que, a depender dos objetivos e escopo da comparação, um exame superficial e pontual de determinado instrumento normativo estrangeiro pode ser suficiente. Muitas vezes, esse é o caso das pesquisas feitas para reformar ou propor alterações legislativas a partir do exame de legislação estrangeira de um país que adota o mesmo sistema jurídico e que partilha dos mesmos princípios e categorias fundamentais no que diz respeito à constituição do direito e da ordem política.

Todavia, para as investigações em Direito Comparado que pretendam examinar normas de um contexto cultural distante ou que ambicionem compreender as diferenças e similaridades de sistemas normativos diversos ou, ainda, que aspirem explicar as razões dessas semelhanças e perculiaridades, é preciso que se tenha um bom conhecimento e que se faça um uso adequado dos vários métodos comparatistas. Mais do que isso, é preciso fazer um uso crítico desses métodos, colocando-se sempre em alerta em relação às limitações e distorções que cada um deles pode impor às análises e analogias que se produz quando se tem a construção cultural e normativa do outro como objeto.

\section{REFERÊNCIAS}


ABBAGNANO, Nicola. Dicionário de Filosofia. Tradução: Ivone Castilho Benedetti. 2. ed. São Paulo: Martins Fontes, 2007.

ANCEL, Marc. Utilidades e métodos do direito comparado. Tradução: Sérgio José Porto. Porto Alegre: Fabris, 1980.

ANDRADE, Daniel de Pádua; PEREIRA, Fabio Queiroz; FERREIRA, Henry G. Colombi B. Direito Comparado e Direito Privado: a tradição brasileira no contexto latino-americano. In: MENEZES, Wagner (org.). Direito Internacional em Expansão. Belo Horizonte: Arraes, 2018.v. 15

BRASIL. Supremo Tribunal Federal. Tribunal Pleno. Embargos infringentes na AP 470. Relator: Min. Luiz Fux, 13 de março de 2014. DJe, Brasília, 20 ago. 2014. Disponível em: https://jurisprudencia.stf.jus.br/pages/search/sjur273403/false. Acesso em: 09 fev. 2021.

BRASIL. Tribunal Regional Federal 1. (3. Turma). Habeas Corpus n. 002876180.2017.4.01.0000. Brasília, 27 jul. 2017. e-DJF1, Brasília, 04 ago. 2017.

CHIESA, Luis E. Comparative Criminal Law. In: DUBBER, Markus D.; HÖRNLE, Tatjana (org.). Oxford Handbook of Criminal Law. Oxford: Oxford University Press, 2014.

DAVID, René. Os Grandes Sistemas do Direito Contemporâneo. Tradução: Hermínio A. Carvalho. 4. ed. São Paulo: Martins Fontes, 2002.

ESTADOS UNIDOS DA AMÉRICA. Suprema Corte dos Estados Unidos. Global-tech appliances, INC. v. SEB S.A. 563 U.S, maio2011.

FRANKENBERG, Günter. Critical Comparisons: Re-thinking Comparative Law. Harvard International Law Journal, v. 26, n. 2, 1985.

GADAMER, Hans-Georg.Verdade e Método:traços fundamentais de uma hermenêutica filosófica.Tradução: Flávio Paulo Meurer. 3. ed. Petrópolis: Editora Vozes, 1999.

HUSA, Jaakko. About the Methodology of Comparative Law - Some Comments Concerning the Wonderland. Maastricht Faculty of LawWorking Paper, Maastricht,n. 5, 2007.

HUSA, Jaakko. Farewell to Functionalism or Methodological Tolerance?Rabels Zeitschrift für ausländisches und internationales Privatrecht, v. 67, n. 3, p. 419-447, jul. 2003.

JANSEN, Nils. Comparative Law and Comparative Knwoledge.In: REIMAN, Mathias; ZIMMERMANN, Reinhard. The Oxford Handbook of comparative Law. Oxford: Oxford University Press, 2006.

KELSEN, Hans. Teoria Pura do Direito.Tradução:João Baptista Machado. 6. ed. São Paulo: Martins Fontes, 1998.

LEGRAND, Pierre. Droit Comparé. Paris: PUF,1999. 
LEGRAND, Pierre. The Same and the Different.In: LEGRAND, Pierre; MUNDAY, Roderick (ed.). Comparative Legal Studies: Traditions and Transitions. Cambridge: Cambridge University Press, 2003. p. 240-311.

LÉVY-STRAUSS, Claude. Antropologia Estrutural.Tradução: Beatriz Perrone-Moisés. São Paulo: Editora Cosac Naify, 2008.

LUCCHESI, Guilherme Brenner. Punindo a culpa como dolo: o uso da cegueira deliberada no Brasil. São Paulo: Marcial Pons, 2018.

MICHAELS, Ralf. The Functional Method of Comparative Law.In: REIMAN, Mathias; ZIMMERMANN, Reinhard. The Oxford Handbook of comparative Law. Oxford: Oxford University Press, 2006.

MORO, Sergio Fernando. Crime de lavagem de dinheiro. São Paulo: Saraiva, 2010.

PRADEL, Jean. Droit penal comparé. Paris: Dalloz, 1995.

REITZ, John C..How to do Comparative Law.The American Journal of Comparative Law, v. 46, 1998.

SAMUEL, Geoffrey. An Introduction to Comparative Law Theory and Method.Oxford: Hart, 2014

VICENTE, Dario Moura. Direito Comparado: introdução, sistemas jurídicos em geral. 4. ed. São Paulo: Almedina, 2018. v. 1.

VOGEL, Joachim. Estado y tendencias de la armonización del derecho penal material en la Unión Europea. Revista Penal, n. 10, p. 112-129, 2002.

WAGNER, Roy. A invenção da Cultura.Tradução:Marcela Coelho de Souza e Alexandre Morales. São Paulo: CosacNaify, 2012.

ZIMMERMANN, Reinhard. Savigny's Legacy.Legal History, Comparative Law and the Emergence of a European Legal Science.Law Quarterly Review, Londres, v. 112, 1996.

ZWEIGERT, Konrad; KÖTZ, Hein.An Introduction to Comparative Law.Tradução: Tony Wair. 3. ed. Oxford: Oxford University Press, 1998. 